\title{
A numerical study of the effects of shot peening on the short crack growth behaviour in notched geometries under bending fatigue tests
}

C. You ${ }^{1 *}$, M. Achintha ${ }^{2}$, B. Y. He${ }^{1}$, P.A.S Reed ${ }^{1}$

${ }^{1}$ Engineering Materials, Faculty of Engineering and the Environment, University of Southampton, Highfield, Southampton, SO17 1BJ, UK

2 Infrastructure Group, Faculty of Engineering and the Environment, University of Southampton, Highfield, Southampton SO17 1BJ, UK

\section{Abstract}

The current paper presents a numerical analysis of the effects of shot peening on short crack growth in a low pressure (LP) steam turbine material, FV448. The fatigue behaviour of this material has been experimentally evaluated using a U-notched specimen (representing the fir tree root geometry of the turbine blade) under 3-point bend tests. Two different shot peening intensities were considered in this study: an industrially applied shot peening process and a less intense shot peening process.

In the modelling work, a 2-D finite element (FE) model with static short cracks has been developed, incorporating both compressive residual stress and strain hardening distribution effects caused by shot peening. Both linear-elastic (LEFM) and elasto-plastic (EPFM) fracture mechanics were used to characterise the crack driving force in the un-peened and shot-peened conditions, taking into account the effects of stress redistribution caused by residual stress relaxation and crack opening. The stress intensity factor used in the LEFM approach was calculated using the weight function method, and the equivalent stress intensity factor used in the EPFM approach was calculated from the J-integral, which was evaluated using the cracked FE model. These results could explain the mechanism of (experimentally observed) retardation of crack growth through the shot-peening-affected layer and also quantified this influence on fatigue life. The relative contributions of compressive residual stresses and strain hardening were assessed by investigating them separately. The sub-surface compressive residual stress distribution produced by shot peening could effectively reduce crack propagation but the strain hardening distribution, in contrast, can accelerate it. However, strain hardening is expected to hinder the crack initiation process by restricting the plastic deformation during cyclic loading. Predictions of the fatigue life of the shot-peened notched specimens were made

\footnotetext{
${ }^{*}$ Corresponding author. Tel.: +44 (7) 448196419

Email address: c.you@soton.ac.uk (C. You)
} 
based on this numerical analysis. Acceptable results were obtained using both the LEFM and EPFM approaches and the difference between them is discussed.

Keywords: Shot peening, short crack, finite element modelling, life prediction

\section{Introduction}

Shot peening is a popular surface treatment method which is used to increase the fatigue resistance of metallic components containing stress concentration features, such as the fir-tree blade-disc interface in turbines. Generally, the shot-peened surface is roughened by the peening process, which is believed to be detrimental to the fatigue resistance since the crack initiation process may be accelerated [1]. On the other hand, the compressive residual stress resulting from shot peening can potentially improve the fatigue resistance by retarding both the crack initiation and propagation processes [2,3], which usually plays a dominant role when surface roughness $R_{a}<5 \mu m$ [4]. In addition, the material near the shot-peened surface is commonly strain-hardened, which also influences the crack initiation and growth behaviour. Some studies have experimentally investigated the effects of strain hardening and concluded that strain hardening mainly retarded crack initiation due to the increased dislocation density of the strain-hardened layer, but there is still controversy over its role in crack propagation $[3,5,6]$.

Classical lifing approaches (i.e. total life and damage tolerant approaches) are typically made without explicit consideration of shot peening effects. In order to improve lifing accuracy while maintaining sufficient safety margins, many researchers have taken shot peening effects into account by modifying the way in which the dependent variables (such as the stress range $\Delta \sigma$, the strain range $\Delta \varepsilon$ and the fracture mechanics parameter $\Delta K$ ) in classical lifing protocols are calculated. Compared with total life approaches [7-10], the application of damage tolerant approaches to the fatigue life prediction of shot-peened components has not been fully investigated. It has been reported that shot peening enhances the fatigue resistance mainly by retarding the crack initiation and short crack growth process, even resulting in non-propagating short cracks $[2,11,12]$. Hence, in order to quantify the benefits of shot peening in improving fatigue life using damage tolerant approaches, accurately characterising the short crack driving force whilst growing through the compressive residual stress and strain hardening field is the most critical issue. A key factor is to ascertain how this is affected by the expected residual stress relaxation behaviour during cyclic loading.

De los Rios et al. [13] predicted the fatigue life of both un-peened and shot-peened samples using an analytical micromechanical model describing short crack growth behaviour, taking into account the effects of the as-peened residual stress and strain hardening. Xiang and Liu [14] applied the equivalent 
initial flaw size (EIFS) concept based on linear-elastic fracture mechanics (LEFM). A linear logarithmic decreasing relationship between surface residual stress and load cycles was also applied in their work to account for the effects of residual stress relaxation. Gao and $\mathrm{Wu}$ [15] predicted the fatigue life of both un-peened and shot-peened samples using the weight function method combined with the FASTRAN approach, a crack closure-based code developed by Newman [16]. In addition, finite element (FE) modelling has also been directly applied in some studies [12, 17-19] due to its advantages in accurately determining the stress and strain distributions within a component under a given loading condition, especially when complex geometries were involved [20]. Guagliano and Vergani [12] developed a 3D FE model and tried to explain the experimentally observed non-propagating short cracks caused by shot peening by considering crack closure effects. Cláudio et al. $[17,18]$ used a 2D FE model to explain the observation of arrested cracks in a shot-peened notched specimen. The crack propagation life was also predicted based on the FE results, which was combined with the predicted crack initiation life to achieve a total life prediction. A similar life prediction method was also employed by Blarasin et al. [19], who additionally validated the applicability of the weight function method when residual stresses were present. Although some predictive success has been achieved in the studies mentioned above, the underlying physics of their methods applied in different systems is still lacking for two reasons: Firstly, the effects of compressive residual stresses in hindering crack growth have been highlighted but the effects of strain hardening have rarely been considered [12, 14, 15, 17-19]. Secondly, the mechanically induced relaxation of the full residual stress profile (not just the surface residual stress) has been ignored in most studies [12-15, 17-19], which may decrease the accuracy of any analysis regarding the short crack growth behaviour through the shot-peening-affected layer [21]. This could be a critical issue especially in the low-cycle fatigue (LCF) regime, where residual stress relaxation is usually significant. In order to improve the accuracy of lifing methods used for shotpeened components and to ensure its applicability in different systems, it is essential to take these two factors into account.

It is also noteworthy that both the linear-elastic and elasto-plastic fracture mechanics (i.e. LEFM and EPFM) have been applied by researchers to study the short crack growth behaviour in specimens treated with shot peening as well as other surface treatments. The general idea is to correlate the short crack data to the baseline long crack data such that the application of the Paris' law can be extended to the short crack regime. Although the elastic assumption of the LEFM approach tends to be invalid for short cracks especially when short cracks are embedded in the plastically deformed area at the notch root, reasonable results can still be obtained by modifying the way in which the stress intensity factors are calculated. One of the popular approaches is by introducing an effective crack length to the definition of the stress intensity factor [14, 22]. The definition of the effective crack 
length is usually related to material parameters or the plastic zone size near the crack tip. Another widely used approach is by defining the effective stress intensity factor range based on the crack closure phenomenon $[15,23,24]$. This approach is usually more convenient especially when the weight function method is applied [25]. In addition, the EPFM approach, which is more appropriate for short crack situations where the size of the plastic zone near the crack tip cannot be ignored compared to the crack size, has also been applied to analyse short crack growth behaviour. The Jintegral has been regarded as a useful elasto-plastic damage parameter and its effective range during cyclic loading can be defined to consider the crack closure effects [17, 26, 27]. However, this method usually requires complicated FE modelling of the crack. Therefore, in order to trade-off between their advantages and disadvantages, a detailed comparison between the LEFM and EPFM approaches is necessary before their application to a specific problem. To the best of the authors' knowledge, no such comparison has been made in studying the fatigue behaviour of shot-peened components.

In this study, a 2D FE model has been developed incorporating both compressive residual stress and strain hardening effects caused by shot peening. This FE model, which can be used to accurately investigate the interaction between the shot-peening-induced effects (i.e. compressive residual stress and strain hardening) and service conditions, is a simplified version of the 3D FE model developed by the authors [28]. In order to understand the benefits of shot peening in retarding short crack growth, residual stress relaxation caused by cyclic loading was first simulated and a stabilised stress and strain state was predicted. Then, cracks with varying lengths were introduced into this stabilised stress and strain field and the crack driving force was characterised using both LEFM and EPFM approaches considering potential crack closure effects; the weight function and the J-integral methods were applied respectively. Compared with the previously reported modelling work, the advantage of this FE model is that strain hardening, as well as residual stress redistribution caused by both "pre-cracking" mechanical loading and the subsequent appearance of the crack, have been taken into account. Hence, the crack growth analysis based on this model is considered to be more reliable. In addition, the relative contributions of the compressive residual stress and strain hardening caused by shot peening to improving fatigue life were also analysed using this FE modelling tool. Finally, the crack propagation life was predicted using both the LEFM and EPFM approaches and a discussion was carried out based on the comparison between the two approaches.

\section{Experiments}

\subsection{Specimen}

The material under investigation is FV448, a 9-12\% $\mathrm{Cr}$ tempered martensitic steel which is representative of the type of material used in low-pressure steam turbine blades. This material is 
typically austenitised at $1150{ }^{\circ} \mathrm{C}$, oil quenched, tempered at $650^{\circ} \mathrm{C}$ and then air cooled. The main monotonic tensile properties of the materials are shown in Table 1. The other mechanical properties, microstructure and composition of this material are detailed in [29]. In this study, a U-notched specimen (stress concentration factor, $K_{t}=1.58$ ) representing the fir tree root geometry of a turbine blade has been used. The dimensions of this specimen are shown in Fig. 1.

Table 1: Monotonic tensile properties of FV448.

\begin{tabular}{ccccc}
\hline$\sigma_{0.2} / \mathrm{MPa}$ & $\sigma_{U T S} / \mathrm{MPa}$ & Strain $(\%)$ at failure & $E / \mathrm{MPa}$ & $v$ \\
\hline $806 \pm 6$ & $987 \pm 9$ & $12 \pm 3$ & $201.3 \mathrm{E}+03$ & 0.3 \\
\hline
\end{tabular}

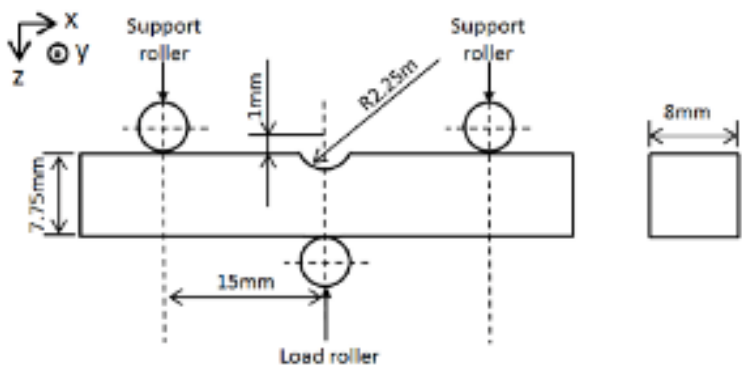

Fig. 1: Dimensions of the U-notched specimen

Before shot peening was applied, the surface of the samples was ground to achieve an initial surface roughness of $R_{a}<0.8 \mu \mathrm{m}$, meeting the industrial machined component (and pre-peen) specification. Two shot peening treatments were used in this study. MI230R 13A 200\% (intensity: 13A, coverage: $200 \%$ ), labelled as T0, was chosen as the baseline shot peening treatment since it was industrially applied to steam turbine blades. Another process, MI110R 04A 200\% (intensity: 4A, coverage: 200\%), labelled as $\mathrm{T} 1$, was considered as a comparison. All the shot peening treatments were carried out by Metal Improvement Company, Derby Division. Experimental residual stress measurements were carried out at the notch root using X-ray diffraction (XRD), accompanied by incremental layer removal via an electro-polishing process to obtain a stress profile into the depth. Details regarding this measurement have been elaborated in $[28,30]$ so are not repeated here. The residual stress distributions caused by the T0 and T1 process at the notch root are shown in Fig. 2, illustrating that the T0 process results in a deeper compressive residual stress layer than the T1 process. In addition, the plastic strain caused by shot peening has been measured using an electron back-scatter diffraction (EBSD) based approach [29]. The results are shown in Fig. 3, illustrating more significant strain hardening effects caused by the T0 process than the T1 process. 


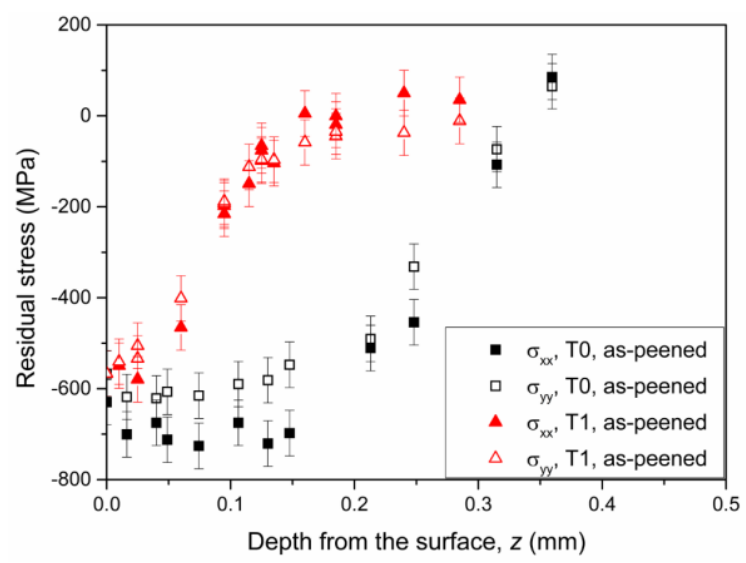

Fig. 2: The compressive residual stress distributions in two orthogonal directions ( $\sigma_{x x}$ and $\sigma_{y y}$ ) caused by the TO and T1 shot peening processes at the notch root (the data for the TO condition were taken from Soady et al. [30]).

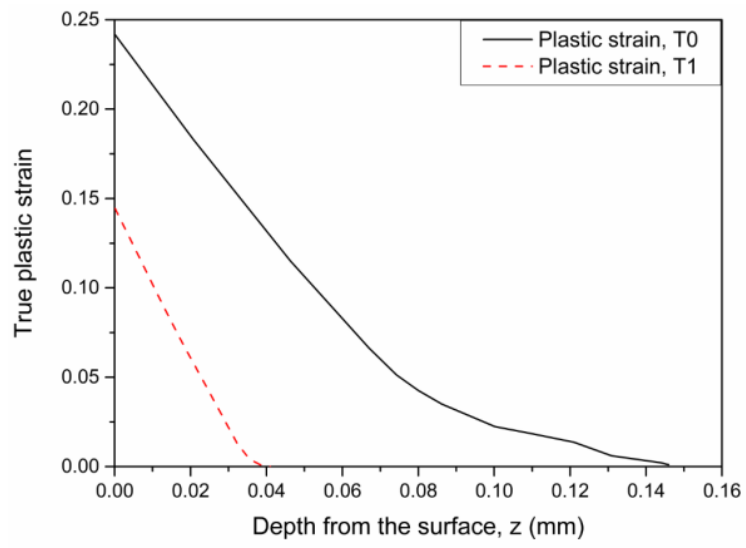

Fig. 3: Predicted true plastic strain distributions caused by the TO and T1 shot peening. After Soady et al. [29].

\subsection{Fatigue tests and results}

All the fatigue tests were carried out at room temperature with a sinusoidal waveform and a frequency of $20 \mathrm{~Hz}$ using a servo hydraulic Instron 8502. The notched specimens were loaded under 3-point bend with a load ratio $R=0.1$. A range of loading levels focusing on the low-cycle fatigue (LCF) regime were selected in this study, considering the service condition at the fir tree root of steam turbine blades, which were likely to experience LCF conditions during repeated start-up and shut-down operations. The true longitudinal strain range, $\Delta \varepsilon_{x x}$, experienced in the centre at the notch root, was estimated using an FE model developed by the authors [28], allowing for the effects of both compressive residual stresses and strain hardening induced by shot peening.

The strain-life $\left(\Delta \varepsilon_{x x}-N_{f}\right)$ plots for the notched sample with different surface treatments (i.e. ground, $\mathrm{T} 1$ and T0 shot peening) are presented in Fig. 4. Compared to the ground condition, it can be seen that the TO process increases the fatigue life of the notched sample at all $\Delta \varepsilon_{x x}$ levels, including the highest one at $\Delta \varepsilon_{x x}=0.81 \%$. By contrast, the $\mathrm{T} 1$ process gives much less benefits in life improvement when $\Delta \varepsilon_{x x}>0.65 \%$. 


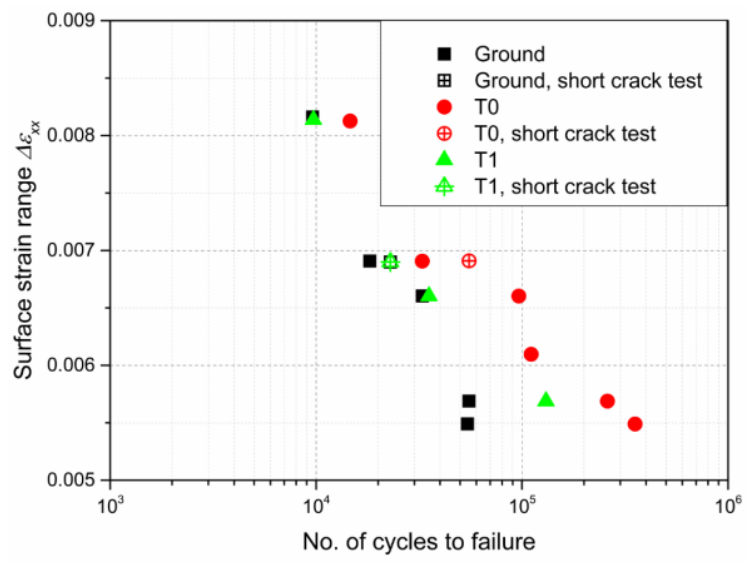

Fig. 4: Strain-life comparison between the notched samples with different surface treatments (fatigue life data reported in Soady et al. [30] were replotted using the FE model incorporating shot-peening effects).

Short crack tests have been carried out at $\Delta \varepsilon_{x x}=0.69 \%$ for specimens treated with grinding, $\mathrm{T} 0$ and T1 shot peening respectively, as indicated in Fig. 4. Replicas have been used to track the surface crack evolution at the notch root and relevant details have been elaborated in [2]. In addition, a relation between the crack aspect ratio $(a / c)$ and the surface crack length $(2 c)$ has also been systematically determined based on experimental observations [2]. This relation was used in combination with the surface crack evolution data to evaluate the crack size $(a)$ evolution in the depth direction, which could not be directly measured in the short crack test. The obtained results are illustrated in Fig. 5, which clearly shows the retardation of the short crack growth behaviour by the TO process compared with the ground condition. By contrast, the T1 process shows no clear benefits in mitigating the crack growth behaviour at this loading level, which is also consistent with the fatigue life data shown in Fig.

4.

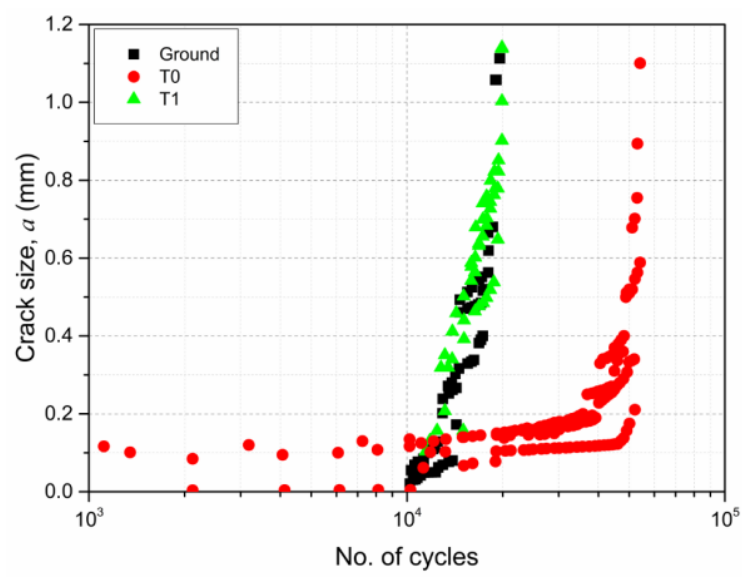

Fig. 5: The predicted crack size evolution in the depth direction at the notch root of the specimens with different surface treatments under $\Delta \varepsilon_{x x}=0.69 \%$. 


\section{Numerical modelling}

\subsection{Modelling of residual stress relaxation}

A 3D FE model incorporating both the compressive residual stress and strain hardening effects induced by shot peening has been developed by the authors. The applied modelling methodologies before the crack is introduced have been elaborated in [28], hence are only briefly introduced here. A non-linear kinematic and isotropic hardening material model was applied to represent the mechanical properties of the material. The compressive residual stress field was reconstructed in the FE model using the inverse eigenstrain method [31]. Modelling of the strain hardening effects was achieved by modifying the mechanical properties of the strain hardened material in the FE model, as a separate step from reconstructing the residual stress field. To realise this modification, the plastic strain distribution caused by shot peening was evaluated based on measurements from an electron back-scatter diffraction (EBSD) based approach [29]. Then, by initialising the material model using the obtained plastic strain distribution, the mechanical properties of the material within the strain hardened layer were modified accordingly in the FE model. This FE model has been demonstrated [28] to be accurate in predicting the observed residual stress relaxation behaviour in two orthogonal directions $\left(\sigma_{x x}\right.$ and $\sigma_{y y}$ ) after the first loading cycle (i.e. quasi-static loading). In the current study, in order to simplify the crack modelling work, a 2D FE model (as shown in Fig. 6) with the plane strain assumption was developed using ABAQUS/Standard (v6.13), following the same modelling procedures of the 3D FE model as elaborated in [28]; only half of the notched specimen was modelled by restricting the longitudinal movement of the central face $\left(U_{x}=0\right)$ for symmetry (the crack was inactivated at this stage by the boundary condition along the crack face). It is noted that only the longitudinal residual stress $\sigma_{x x}$ has been considered in the 2D modelling work and the effects of the transverse residual stress $\sigma_{y y}$ on fatigue life were omitted, although a $20 \%$ relaxation of $\sigma_{y y}$ was experimentally observed during the first cycle [30]. This simplification was assumed reasonable because $\sigma_{x x}$, which was along the loading direction and was normal to the mode I crack opening direction, plays a more dominant role in fatigue life. 


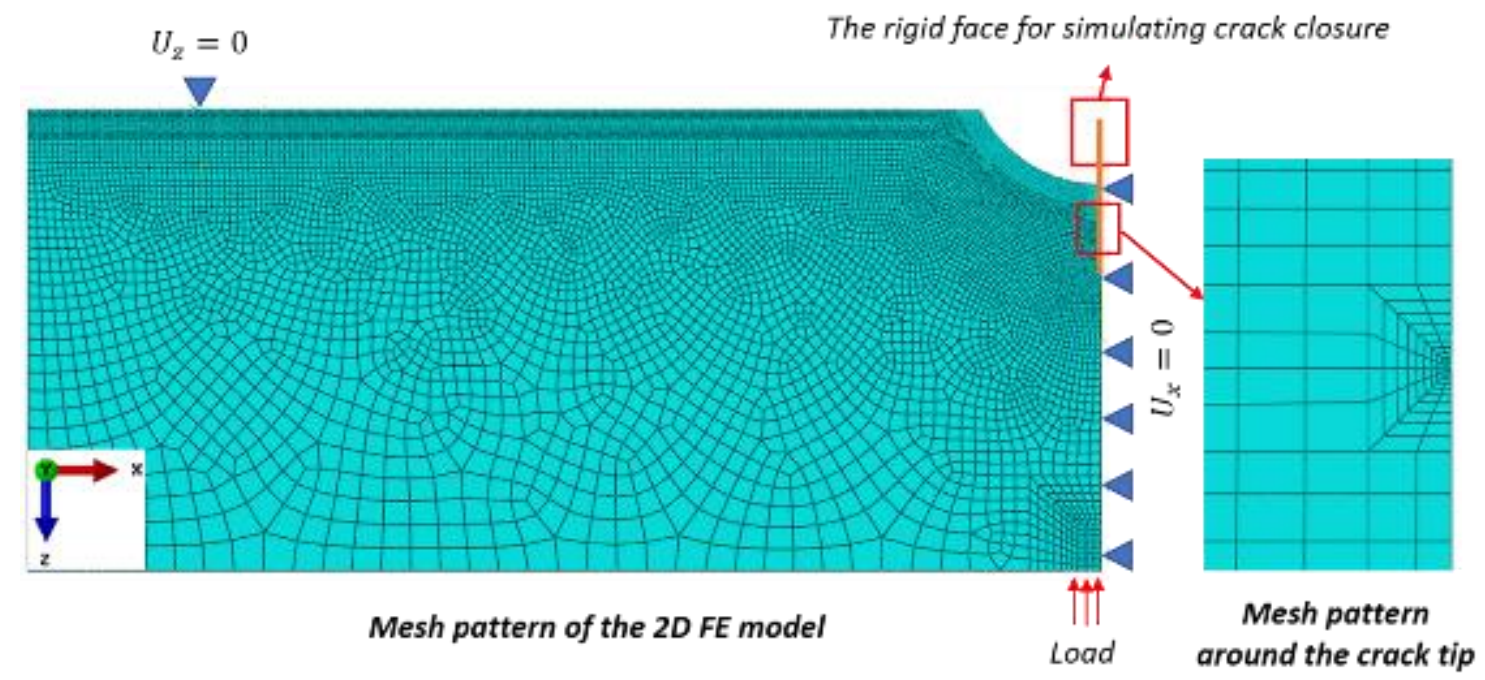

Fig. 6: The 2D FE model of the notched specimen.

Before the cracks were activated, the 2D model was validated by both experimental measurements and $3 \mathrm{D}$ modelling results in reconstructing the as-peened residual stress field and in predicting residual stress relaxation after the first loading cycle under $\Delta \varepsilon_{x x}=0.69 \%$. In the 2D and 3D modelling work, residual stress data were extracted from the notch root area where experimental measurements were carried out. The comparison between experimental and modelling results are shown in Fig. 7. Fig. 7(a) illustrates the residual stress distribution caused by the first loading cycle in the ground specimen; it is noted that the initial surface condition caused by the grinding process was not considered in the modelling work because its effects tended to be easily overcome by external loads under the current circumstances [30], therefore, the ground condition was considered simply as the un-peened condition in this modelling work. In addition, Fig. $7(\mathrm{~b})$ and (c) illustrate the residual stress distribution in the T1 and T0 as-peened conditions respectively. Fig. 7(d) shows the relaxation in residual stress after one cycle in the T0 specimen. According to Fig. 7, the $2 \mathrm{D}$ modelling results are consistent with the 3D modelling and experimental results in both residual stress reconstruction (Fig. 7(b) and (c)) and prediction (Fig. 7(a) and (d)), especially when $z<0.3 \mathrm{~mm}$. Hence, the 2D FE model applied in the current research was deemed reliable. The comparison between the two FE models has also been extended to other $\Delta \varepsilon_{x x}$ levels and similar consistency has been found, further demonstrating the reliability of the 2D FE model. 

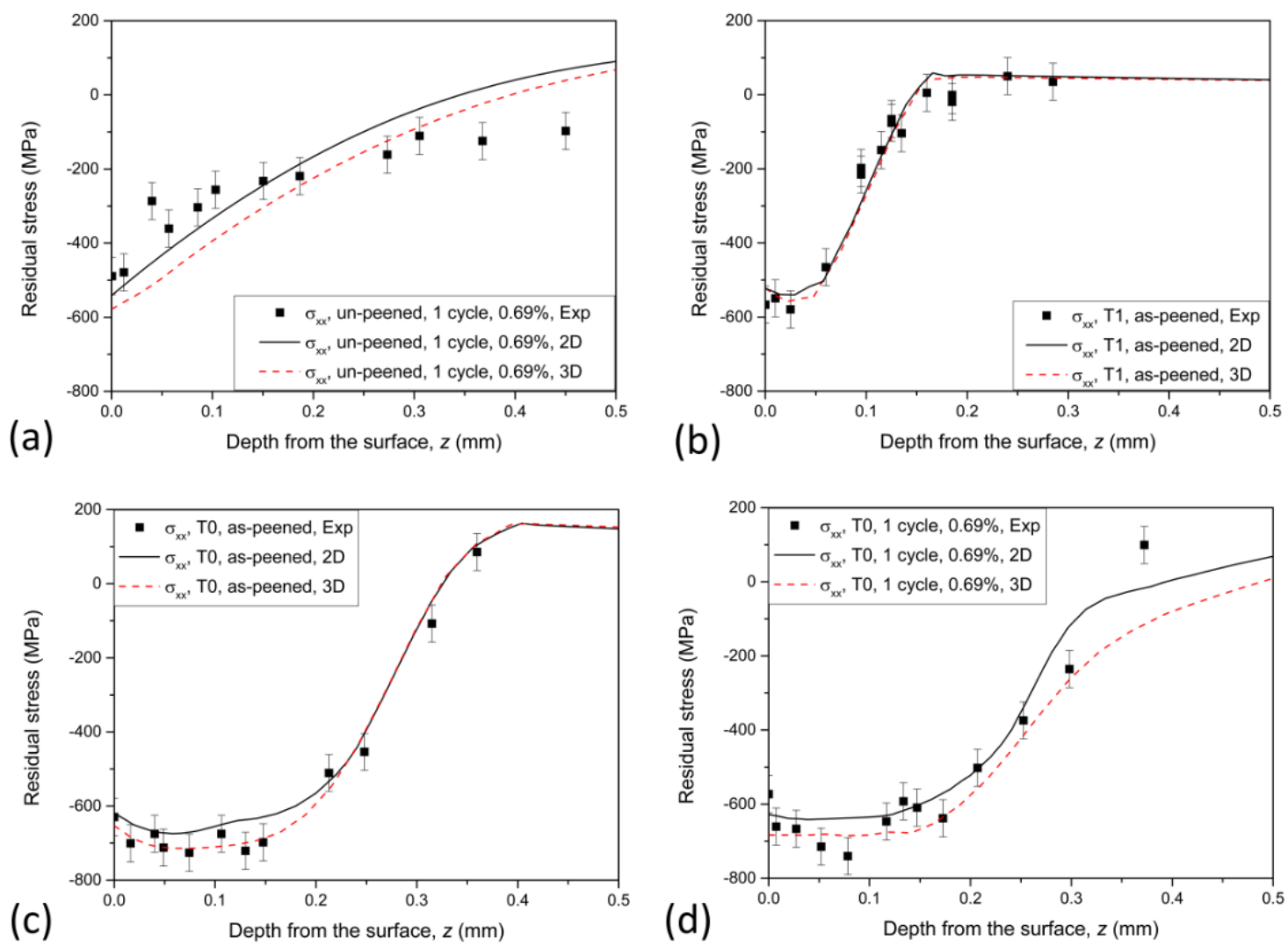

Fig. 7: Comparison between the XRD measurements, 2D and 3D modelling of the residual stress profile $\left(\sigma_{x x}\right)(a)$ in the unpeened condition after 1 loading cycle $\left(\Delta \varepsilon_{x x}=0.69 \%\right),(b)$ in the T1 as-peened condition, (c) in the T0 as-peened condition and $(d)$ in the TO condition after 1 loading cycle $\left(\Delta \varepsilon_{x x}=0.69 \%\right)$.

It is noted that the FE approach applied in the present study is only capable of predicting the stress and strain evolution during the quasi-static loading stage (the first cycle) without considering the cyclic behaviour [28]. The predicted stress and strain field after the first cycle was assumed representative of the stabilised state during cyclic loading under the current circumstances, because our previous experiments had demonstrated that residual stress relaxation mainly occurred during the quasi-static loading stage at the notch root in the low-cycle fatigue (LCF) regime in this material [30]. Plastic deformation in the first loading cycle tended to significantly reduce the plastic misfit within the surface layer, which is the source of residual stresses. Similar results have also been reported by others [32, 33].

\subsection{The linear-elastic fracture mechanics (LEFM) approach}

The LEFM approach applied in this study was based on calculating stress intensity factors using the weight function method, which was derived from the knowledge of the stress distribution present in the un-cracked geometry [25]. The stress intensity factor $K$ for a given geometry under arbitrary loading is expressed by Equation 1, where $\sigma(z)$ is the stress distribution acting in the normal direction to the crack plane and $m(a, z)$ is a weight function associated with the crack length $a$ and the 
coordinate $z$ along the crack face. $m(a, z)$ depends only on the geometry and boundary conditions and is independent of the magnitude and type of external loads. The weight function $m(a, z)$ for the notched geometry shown in Fig. 1 has been determined following the method introduced in [25].

$K=\int_{0}^{a} \sigma(z) m(a, z) d z$

Shot peening effects were considered by the weight function method based on the concept of superposition. The effective stress intensity factor, $K_{e f f}$, can be determined by superposing the applied stress intensity factor due to external load, $K_{a p p}$, and the residual stress intensity factor, $K_{\text {res }}$, as described by Equation 2. $K_{a p p}$ was calculated using the stress profile caused by external loads, $\sigma_{a p p}(x)$, which was predicted using an elastic FE model without considering shot peening effects. $K_{\text {res }}$ was determined using the stabilised residual stress profile, $\sigma_{\text {res }}(x)$, which was predicted using an elasto-plastic FE model as introduced in Section 3.1.

$K_{\text {eff }}=K_{\text {app }}+K_{\text {res }}$

Cracks with varying lengths ( $a \leq 1.6 \mathrm{~mm}$ ) were considered in this study and the chosen range of the crack size was estimated to cover the regime of steady crack growth beyond which unsteady crack propagation happened. In order to take the potential crack closure effects caused by compressive residual stresses into account, $K_{\text {eff_min }}$ was taken to be zero at the minimum load when a negative value was obtained using Equation 2. The effective stress intensity factor range during cyclic loading, $\Delta K_{e f f}$, was then determined according the loading range, as expressed by Equation 3.

$\Delta K_{e f f}=K_{e f f_{\_} \max }-K_{\text {eff_min }}$

\subsection{The elasto-plastic fracture mechanics (EPFM) approach}

The EPFM approach has been applied in order to make a comparison with the LEFM approach in understanding the effects of shot peening on the short crack growth behaviour. Static cracks with varying lengths ( $a \leq 1.20 \mathrm{~mm}$ ) have been introduced into the 2D FE model. The mesh pattern around the crack tip is illustrated in Fig. 6 and the mesh size at the crack tip is $1 \mu m$. A mesh sensitivity analysis has been carried out to ensure that the crack modelling results are independent of the mesh size at this mesh density level. The crack driving force was characterised in terms of the J-integral which was calculated automatically by ABAQUS. Although the conventionally defined J-integral becomes pathdependent in the residual stress field, a local path-independence can still be achieved near the crack tip as long as the mesh is fine enough, and the corresponding value of the J-integral can still accurately represent the crack driving force [24, 34, 35]. This local path-independence of the J-integral has been achieved in the current modelling work and used to estimate the equivalent stress intensity factor, 
$K_{p}$, as expressed by Equation 4, where $E$ is the Young's modulus and $v$ is the Poisson's ratio of FV448. It is noted that $K_{p}$ does not have direct physical meaning in the EPFM approach and has been used simply as an equivalent parameter to make a comparison with $K$ which has been estimated using the LEFM approach.

$K_{p}=\sqrt{\frac{J E}{1-v^{2}}}$

In the modelling work, the procedure of introducing a crack into the shot-peening-affected area is illustrated in Fig. 8. Since crack initiation usually occurs after the stabilisation of the stress and strain state during cyclic loading, the introduced crack was initially inactivated during the first cycle in the modelling work by applying boundary conditions for symmetry along the crack face. Then the "uncracked" model was used to predict the stabilised stress and strain state by simulating the residual stress relaxation behaviour, as introduced in Section 3.1. Finally, the boundary conditions along the crack face were removed and the crack was activated. By applying another loading cycle, the stress and strain redistribution around the crack tip during crack opening was simulated. The potential crack closure phenomenon caused by compressive residual stresses was modelled by defining a normal contact between the crack face and a rigid face fixed on the right hand side of the model (the central face of the real specimen) to avoid the overlapping effects, as shown in Fig. 6. The contact was assumed to be frictionless, which was reasonable since only the mode I crack was considered in this study. The $K_{p}$ value at which the crack was fully open (i.e. $K_{p_{-} o p}$ ) was determined when the contact force became zero. The effective equivalent stress intensity factor range, $\Delta K_{p_{-} e f f}$, was then calculated using Equation 5, considering the crack closure effects.

$\Delta K_{p_{-} e f f}=K_{p_{-} \max }-K_{p_{-} o p}$

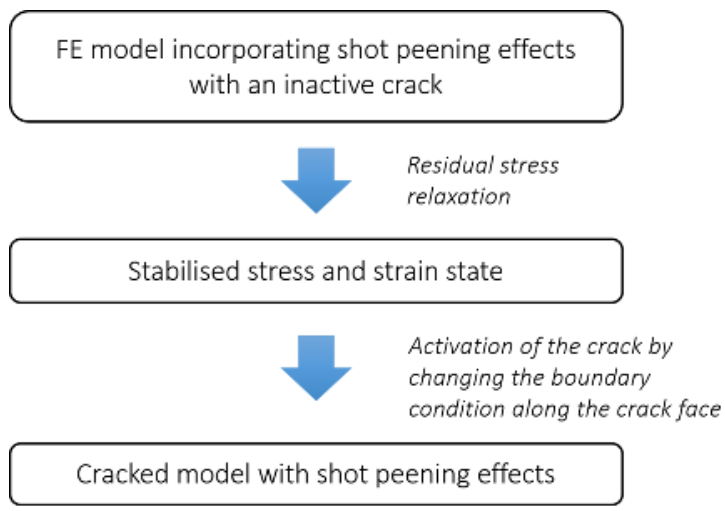

Fig. 8: Procedure of introducing a crack into the shot-peening-affected area. 


\section{Modelling results and discussion}

\subsection{Residual stress relaxation}

The simulated residual stress relaxation after one cycle under different loading levels $\left(\Delta \varepsilon_{x x}=0.57 \%\right.$, $0.66 \%, 0.69 \%$ and $0.81 \%$ ) for different surface conditions (i.e. un-peened, T0 and T1 shot peening) are shown in Fig. 9. In the un-peened condition, as shown in Fig. 9(a), the magnitude of the compressive residual stress increases with increasing loading levels due to the generated plastic misfit between layers. In the TO and T1 conditions illustrated in Fig. 9(b) and (c) respectively, there is no clear relaxation of $\sigma_{x x}$ during the first cycle and the depth of the compressive residual stress profile even increases with increasing loading levels. In fact, this is not surprising in the 3-point bend case: the inhomogeneous plastic deformation generated by the bending process itself develops a compressive residual stress layer after unloading as a result of the constraint exerted by the elastically deformed material beneath. This process tends to be more significant in the notched geometry and compensates for any compressive residual stress relief occurring in the loading $\left(\sigma_{x x}\right)$ direction [28].
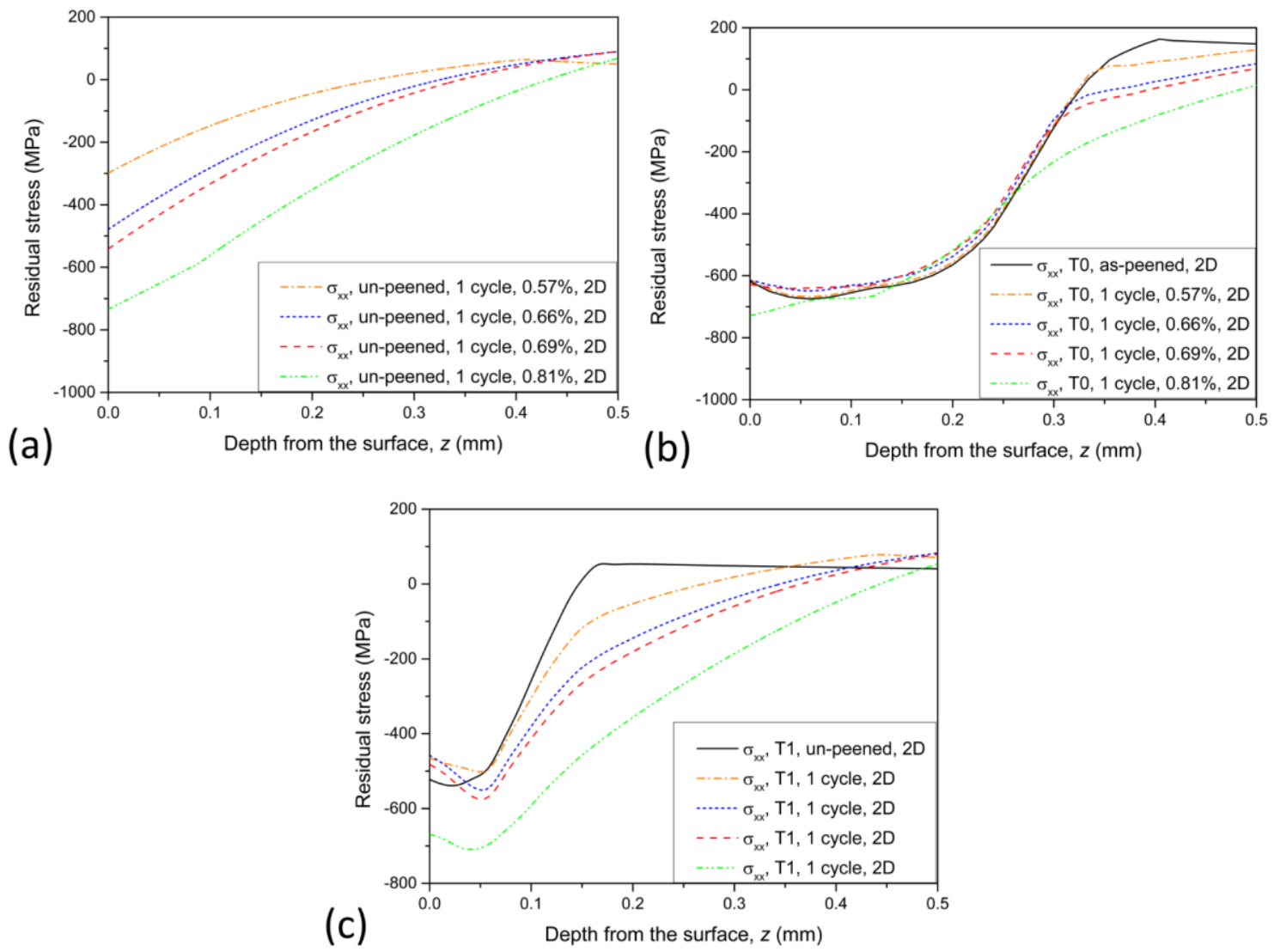

Fig. 9: The predicted residual stress $\left(\sigma_{x x}\right)$ distributions at the notch root after one cycle for samples with different surface conditions: (a) un-peened, (b) TO and (c) T1 shot peening. 
4.2. The effects of compressive residual stress and strain hardening on crack growth

The calculated crack driving force ( $\Delta K_{e f f}$ in LEFM and $\Delta K_{p_{-} e f f}$ in EPFM) for cracks in the un-peened, T0 and T1 conditions are shown in Fig. 10; the effects of varying loading levels $\left(\Delta \varepsilon_{x x}=0.57 \%, 0.69 \%\right.$ and $0.81 \%$ ) have been investigated. As illustrated in Fig. 10, both the LEFM and EPFM approaches show similar results in terms of the trend of the data; compared with the un-peened condition, the crack driving force is reduced by shot peening by varying degrees depending on the peening intensity and the loading level.

Fig. 10(a) and (b) demonstrate the results obtained at $\Delta \varepsilon_{x x}=0.57 \%$ using the LEFM and EPFM approaches respectively. Compared with the un-peened condition, it can be seen that the TO process significantly reduces the crack driving force. The T1 process also maintains noticeable beneficial effects at this loading level, although less benefit is observed than the TO process. When the loading level is increased to $\Delta \varepsilon_{x x}=0.69 \%$, the benefits of the T1 process in reducing the crack driving force are significantly reduced, although the T0 process still provides noticeable benefits, as shown in Fig. 10 (c) and (d). At the highest loading level (i.e. $\Delta \varepsilon_{x x}=0.81 \%$ ), the effects of the T1 process completely disappear and the TO process only provides very limited benefits compared with at the lower loading levels. The discrepancy between the effects of the TO and T1 processes can be explained by the predicted stabilised residual stress state shown in Fig. 11, which illustrates that greater levels of compressive residual stresses are retained in the TO condition than the T1 condition, especially at high loading levels where external loads tend to eliminate the effects resulting from the T1 process. The results of this numerical analysis are consistent with the observed trend in fatigue life difference between the ground and shot-peened specimens shown in Fig. 4; the improvement of the fatigue life of the ground specimen by both T0 and T1 processes gradually decreases with increasing loading levels, especially the T1 process whose benefits in improving fatigue life are comparatively less significant than the T0 process and become very limited when $\Delta \varepsilon_{x x}>0.65 \%$. 

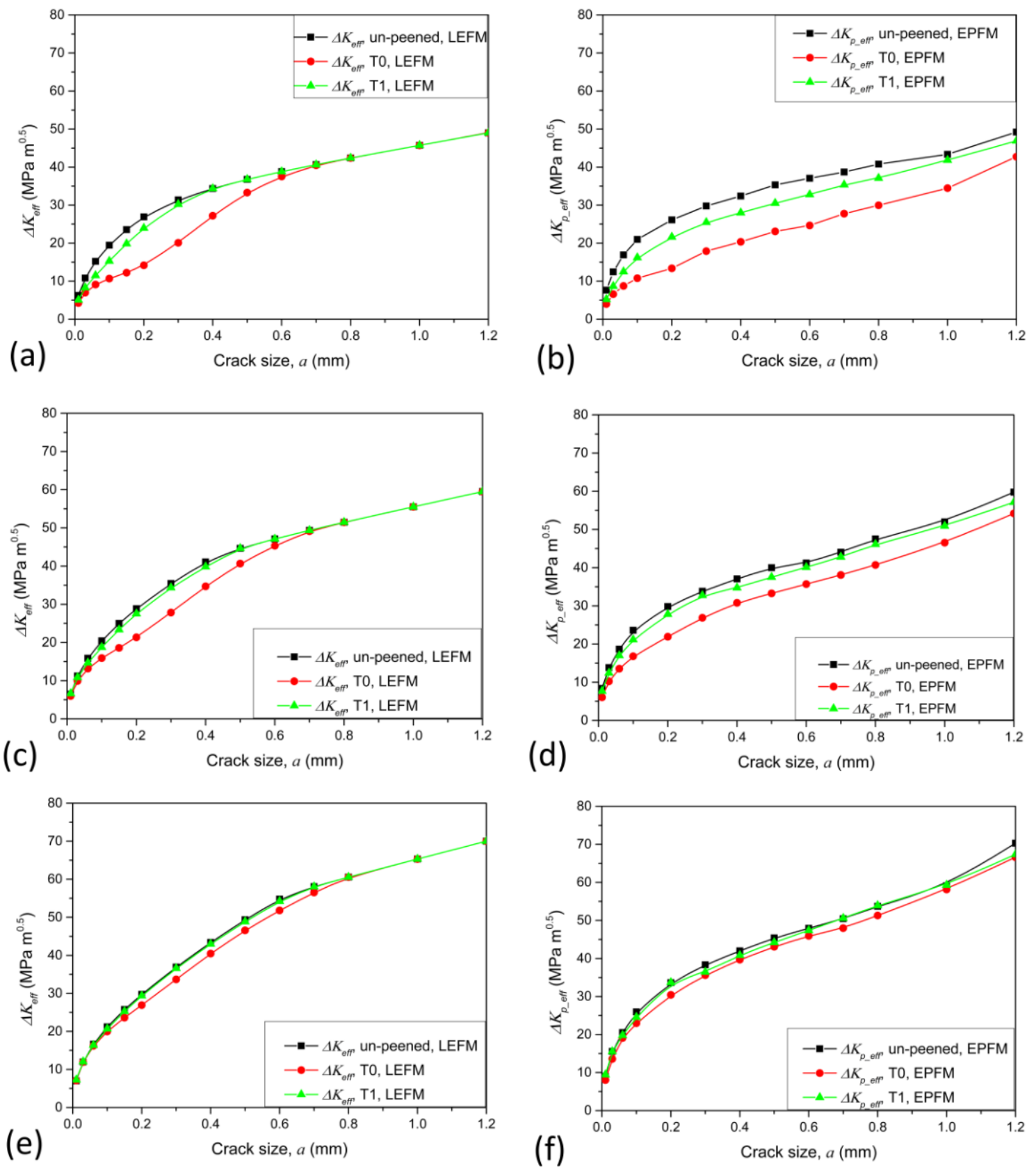

Fig. 10: The comparison between the un-peened and shot peening conditions (TO and T1) in the calculated $\Delta K_{\text {eff }}$ (or $\Delta K_{p_{-} \text {eff }}$ ) for different crack lengths under varying loading levels: $(a)(b) \Delta \varepsilon_{x x}=0.57 \%$, (c)(d) $\Delta \varepsilon_{x x}=0.69 \%$ and $(e)(f) \Delta \varepsilon_{x x}=$ $0.81 \%$, using both the $(a)(c)(e)$ LEFM and $(b)(d)(f)$ EPFM approaches. 

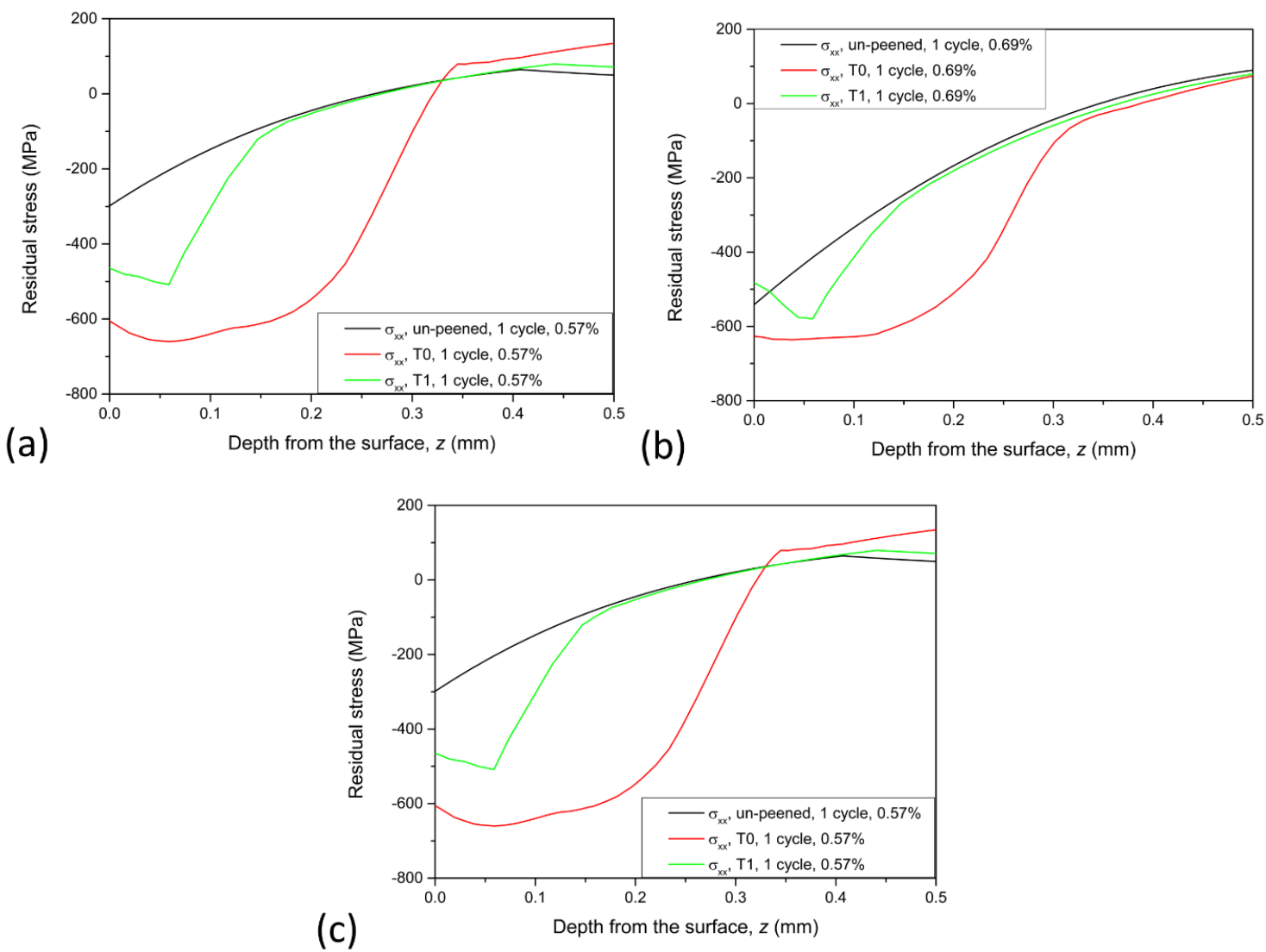

Fig. 11: Comparison between the predicted stabilised residual stress distributions in the un-peened, T1 and TO shot-peened specimens using the 2D FE model: (a) $\Delta \varepsilon_{x x}=0.57 \%$, (b) $\Delta \varepsilon_{x x}=0.69 \%$ and (c) $\Delta \varepsilon_{x x}=0.81 \%$.

It is noteworthy that the effects of shot peening illustrated in Fig. 10 result from the combined influence of strain hardening and compressive residual stresses caused by the shot peening process. It is easily intuitive to understand that the compressive residual stress tends to hinder both the crack initiation and propagation processes by counteracting the tensile stress exerted by external loads. Nevertheless, the mechanism of the effects of strain hardening are more complex to understand, as discussed in Section 1. In the current study, to improve the understanding of the influence of shot peening on crack growth, the effects of compressive residual stresses and strain hardening have been investigated individually in the FE modelling work. To achieve this, the approaches of modelling the strain hardening and compressive residual stress effects (as introduced in Section 3.1) have been applied separately in two FE models. The corresponding crack driving forces were calculated respectively using the EPFM approach. The modelling results for the TO shot peening condition under $\Delta \varepsilon_{x x}=0.69 \%$ are shown in Fig. 12 as an example and consistently similar trends were also found for other shot peening or loading conditions in the current study. It can be seen that the compressive residual stress makes a significant contribution to the beneficial effects of shot peening in decelerating crack propagation, which reinforces the current commonly held understanding. Conversely, strain hardening increases the crack driving force compared with the un-peened condition. This is 
reasonable in a load-controlled bending test since the stress level in the strain-hardened layer is increased (as shown in Fig. 13(a)) due to the increased yield strength of the material, which may result in higher energy release rate when the crack propagates through this layer. In addition, the effects of strain hardening on crack initiation were also investigated by predicting the plastic strain $\left(\varepsilon_{p_{-} x x}\right)$ distribution at the peak load using the "un-cracked" FE model. As illustrated in Fig. 13(b), the $\varepsilon_{p_{-} x x}$ distribution at the notch root is reduced by the strain hardening effects although the stress level has been increased (as shown in Fig. 13(a)), implying a hindered crack initiation process.

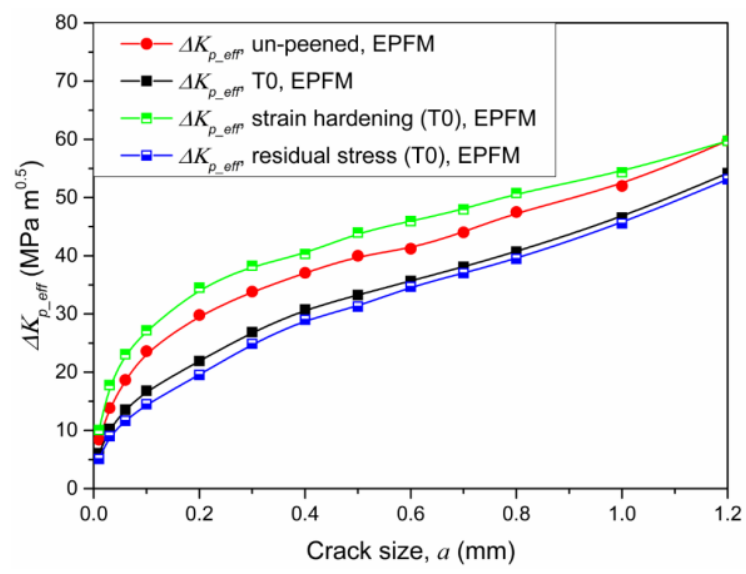

Fig. 12: Relative importance of the strain hardening and residual stress effects caused by the T0 shot peening process on

$$
\Delta K_{p_{-} e f f} \text { at } \Delta \varepsilon_{x x}=0.69 \% \text {. }
$$
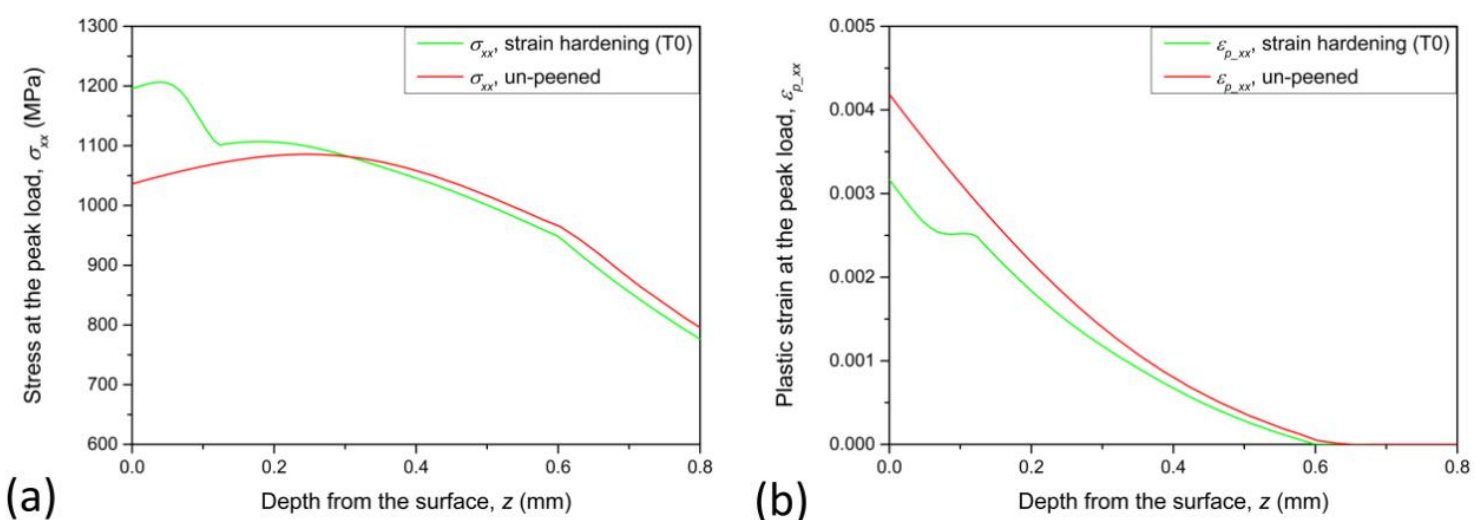

Fig. 13: Comparison in the predicted longitudinal (a) stress $\left(\sigma_{x x}\right)$ and (b) plastic strain $\left(\varepsilon_{p_{-} x x}\right)$ distribution at the notch root between the un-peened and strain hardening (TO) condition at the peak load of $\Delta \varepsilon_{x x}=0.69 \%$.

\subsection{Life prediction}

When evaluating the fatigue life of shot-peened specimens, the influence of shot peening on crack growth has to be explicitly taken into account in order to ensure the accuracy of the life prediction results. In the current study, the numerical results elaborated in Section 4.2 have been applied in life prediction procedures used for the shot-peened samples. 
The crack growth rates $(\mathrm{d} a / \mathrm{d} N)$ in the ground, TO and T1 shot-peened conditions have been characterised based on the calculated $\Delta K_{a p p}, \Delta K_{\text {eff }}$ and $\Delta K_{p_{-} e f f}$. The results are shown in Fig. 14(a), (b) and (c) respectively along with the Paris' law for the material under investigation (i.e. FV448); the Paris' law was determined as $C=1.66 \times 10^{-9} \mathrm{~mm} \mathrm{cycle}^{-1}$ with the upper and lower limit of $6.74 \times$ $10^{-10}<C<4.1543 \times 10^{-9} \mathrm{~mm}$ cycle $^{-1}$ and $m=3.3$ [36]. The data shown in Fig. 14 are quite scattered which is a typical feature of short crack data. It is interesting to note that the data for the ground, T1 and T0 shot-peened samples form a more merged scatter band considering the shot peening effects using $\Delta K_{\text {eff }}$ or $\Delta K_{p_{-} e f f}$ (compared to the data obtained when plotted in terms of $\Delta K_{a p p}$ calculated from global loading assumption), and on the whole, now better follow the trend determined by the Paris' law in spite of the scatter of the data. This indicates the possibility of extending the application of the Paris' law to the short crack regime in the shot-peened condition. It is noted that the $\mathrm{d} a / \mathrm{d} N$ values were determined according to Fig. 5 , where the crack length $(a)$ data were not directly measured, but were predicted based on the tracked surface crack growth data, due to the lack of reliable quantitative experimental data describing crack propagation into the bulk of the material. This may introduce some errors to the obtained $\mathrm{d} a / \mathrm{d} N$.
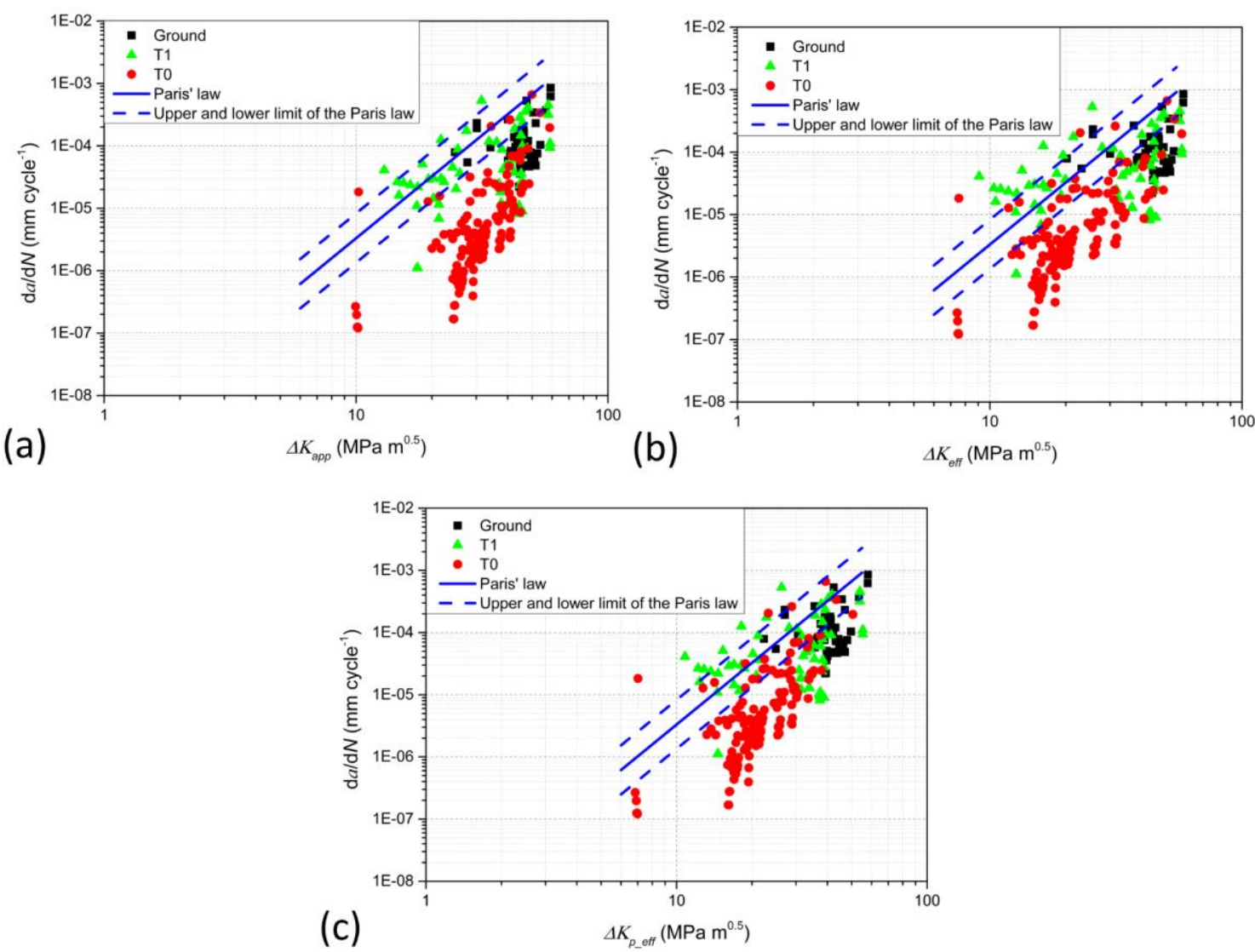

Fig. 14: Plot of the crack growth rate (da/dN) using the (a) $\Delta K_{a p p}$, (b) $\Delta K_{\text {eff }}$ and (c) $\Delta K_{p_{-} e f f}$. 
In the current study, the crack propagation life of the shot-peened samples have been predicted using the Paris law in combination with the modelling results regarding the crack driving force shown in Fig. 10. The initial crack size, $a_{0}$, was assumed to be $0.005 \mathrm{~mm}$. The critical crack length, $a_{c}$, was estimated to be within the range of $0.8-1.2 \mathrm{~mm}$ depending on the specific loading level, by equalising $K_{\text {eff }}$ (or $\left.K_{p_{-} e f f}\right)$ to the $K_{I C}\left(55.3 \mathrm{MPa} \mathrm{m}^{0.5}\right)$ of FV448. The predicted crack growth behaviour at $\Delta \varepsilon_{x x}=0.69 \%$ in the ground, T0 and T1 conditions are shown in Fig. 15 in comparison with experimental results. It can be seen that although there is a difference between experimental and predicted results, both LEFM and EPFM approaches successfully predict more significantly retarded short crack growth behaviour due to the T0 process than the T1 process. This work has been carried out for different $\Delta \varepsilon_{x x}$ levels. The resultant life prediction results are shown in Fig. 16, illustrating that the experimentallyobserved difference in fatigue life between samples with different surface treatments is successfully predicted.

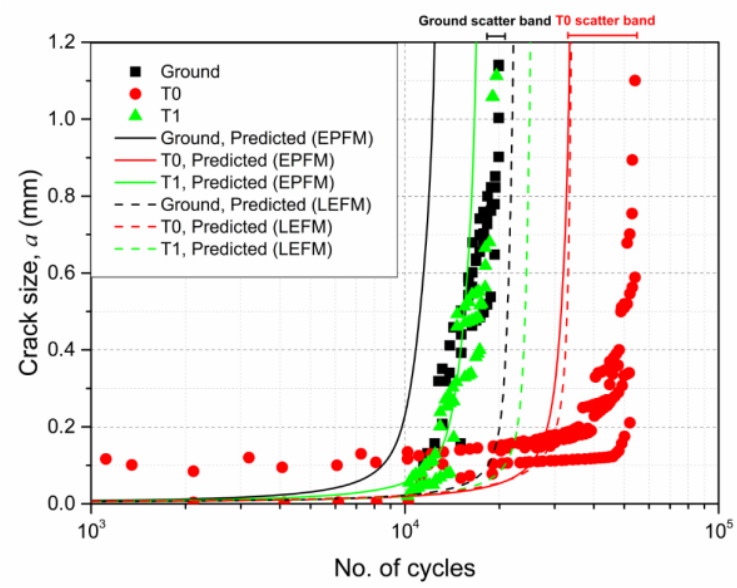

Fig. 15: Comparison between the experimental and predicted crack growth behaviour in the ground, T0 and T1 conditions at $\Delta \varepsilon_{x x}=0.69 \%$; the scatter band was determined based on results of repeated tests at this loading level, as shown in Fig. 4 .

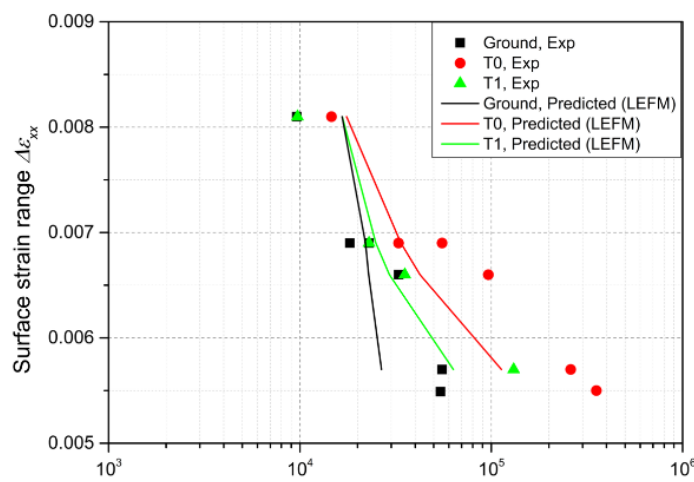

(a)

No. of cycles to failure

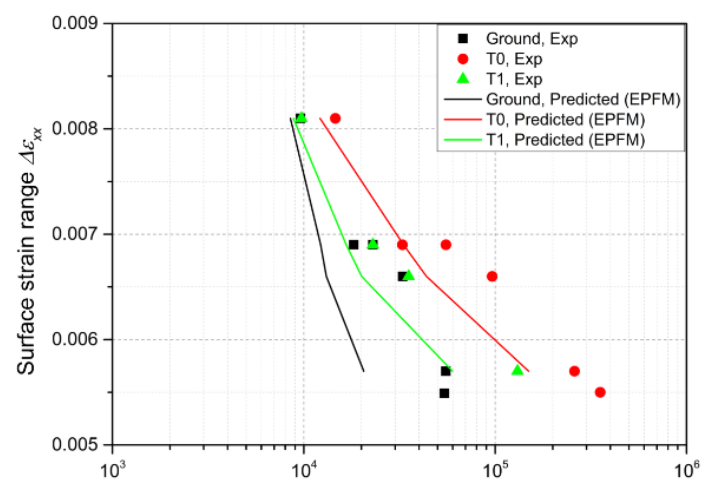

(b)
No. of cycles to failure

Fig. 16: Comparison between the experimental and predicted fatigue lives using (a) LEFM and (b) EPFM approaches.

The errors of this life prediction are illustrated in Fig. 17 along with an investigation regarding the effects of $a_{0}\left(a_{0}=0.005,0.01\right.$ and $\left.0.02 \mathrm{~mm}\right)$ on the predicted life. Again, both the LEFM and EPFM 
approaches have been applied and the results for the T0 and T1 conditions are shown in Fig. 17 (a)(b) and Fig. 17 (c)(d) respectively. According to Fig. 17, as expected, smaller $a_{0}$ results in a longer fatigue life at each loading level, and compared with the experimental results, most of the predicted results in the LCF regime $\left(N_{f}<10^{5}\right)$ are within the factor of two error range regardless of the chosen $a_{0}$, demonstrating the life prediction can take account of these varying (realistic) initial defect sizes whilst still producing comparable lifetimes to those observed experimentally. However, it is noteworthy that LEFM tends to result in non-conservative fatigue lives when $\Delta \varepsilon_{x x}>0.69 \%$, which is a clear drawback. It can also be seen that compared with the experimentally determined fatigue lives, the model tends to underestimate the lifetimes around $10^{5}$ cycles or more (the medium- to high-cycle fatigue regime). This underestimation may be attributed to the crack initiation process which was not taken into account in the lifing procedure: At higher loading levels, cracks are expected to appear in the early stages of fatigue life at surface (or near surface) stress concentration sites, such as inclusions or surface imperfections introduced by shot peening, especially in the notched area $[13,15,17,37]$. Hence the LCF life is dominated by crack propagation so that ignoring crack initiation can still result in acceptable life prediction results. However, with decreasing loading levels and prolonged fatigue lives, crack initiation gradually takes a greater proportion of the total fatigue life, therefore, ignoring the initiation stage will result in underestimation of the fatigue life. In addition, it is noted that the fatigue life data are expected to exhibit intrinsic scatter which was not considered in Fig. 17 due to the limitations of the available experimental data (i.e. only one experimental fatigue life data point was considered for each loading level). 

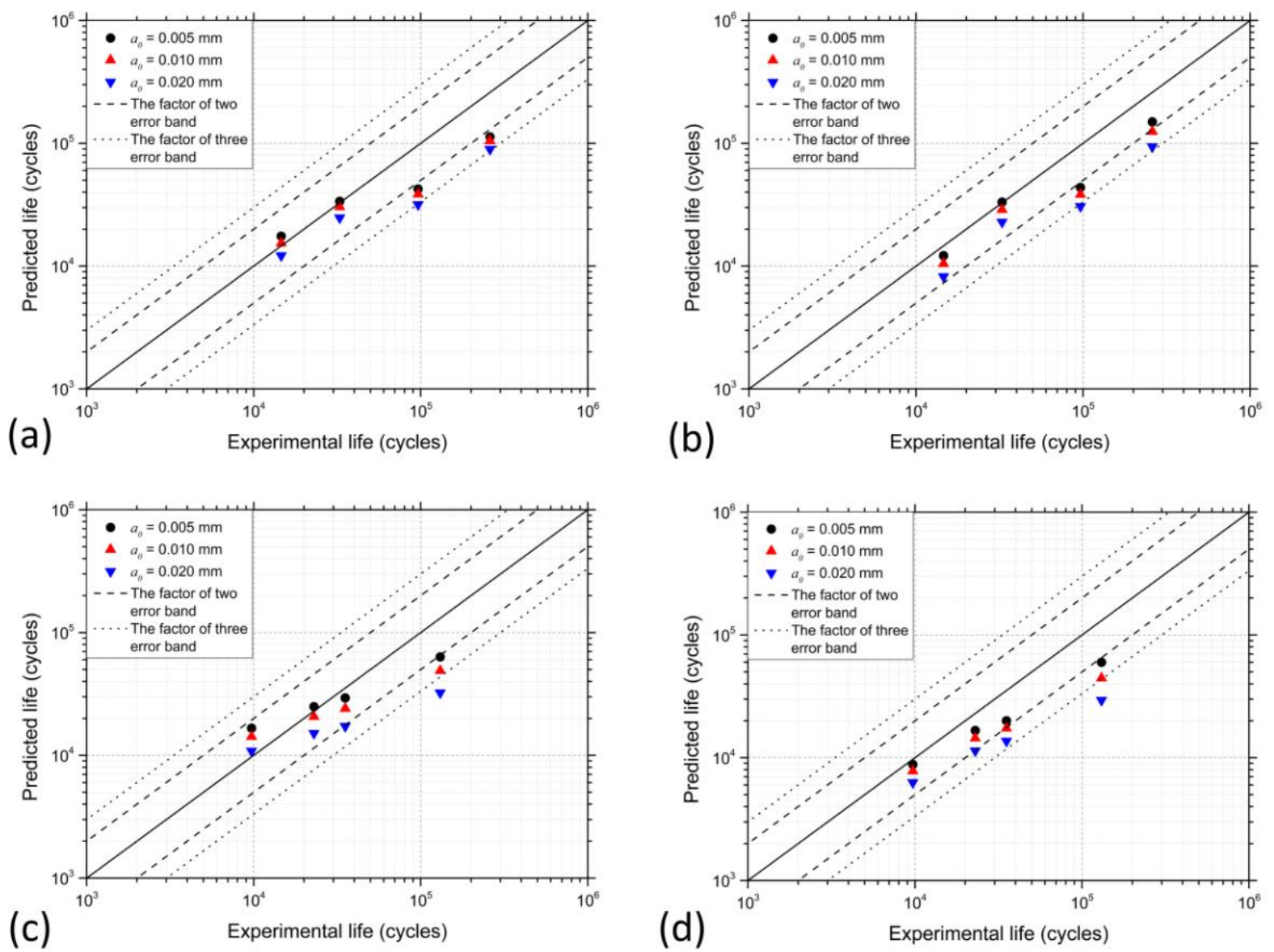

Fig. 17: Comparison between the experimental and predicted fatigue lives of the TO shot-peened samples using (a) LEFM and (b) EPFM, and of the T1 shot-peened samples using (c) LEFM and (d) EPFM.

\subsection{Recommendations for application}

As discussed in Section 4.3, similar but diverse results have been obtained using the LEFM and EPFM approaches, with the main difference observed at high loading levels. The two approaches are directly compared in this section in order to assess their relative merits. In Fig. 18, $K_{p_{-} \max }$ and $K_{\max }$ for cracks in the TO condition at the peak load of $\Delta \varepsilon_{x x}=0.81 \%$ and $0.57 \%$ are compared. It shows that at $\Delta \varepsilon_{x x}=$ $0.81 \%, K_{p_{-} \max }$ is $10-20 \%$ higher than $K_{\max }$ when $a<0.5 \mathrm{~mm}$. This implies that the assumption of LEFM is likely to be invalid for short cracks at this loading level, where the plastic deformation around the crack tip cannot be ignored, although compressive residual stresses have been introduced by shot peening to counteract the external tensile stress. Since the major crack growth life is normally spent in short crack growth, the underestimation of the crack driving force by LEFM at such high loading levels accounts for the consequent non-conservative life prediction (as shown in Fig. 16 and Fig. 17). By contrast, when $\Delta \varepsilon_{x x}$ decreases to $0.57 \%$, the difference between $K_{p_{-} \max }$ and $K_{\max }$ becomes negligible (as shown in Fig. 18), demonstrating the consistency between LEFM and EPFM at low loading levels. A similar situation has also been obtained in the un-peened and T1 shot peening 
conditions. Therefore, it can be concluded that EPFM is more reliable than LEFM in the LCF regime. But in the medium- to high-cycle fatigue regime, the consistency between LEFM and EPFM approaches can be ensured. Under such circumstances, the LEFM approach is deemed more advantageous than the EPFM approach in facilitating the lifing procedure, because the value of $K$ can be conveniently determined using the weight function method without complex crack modelling.

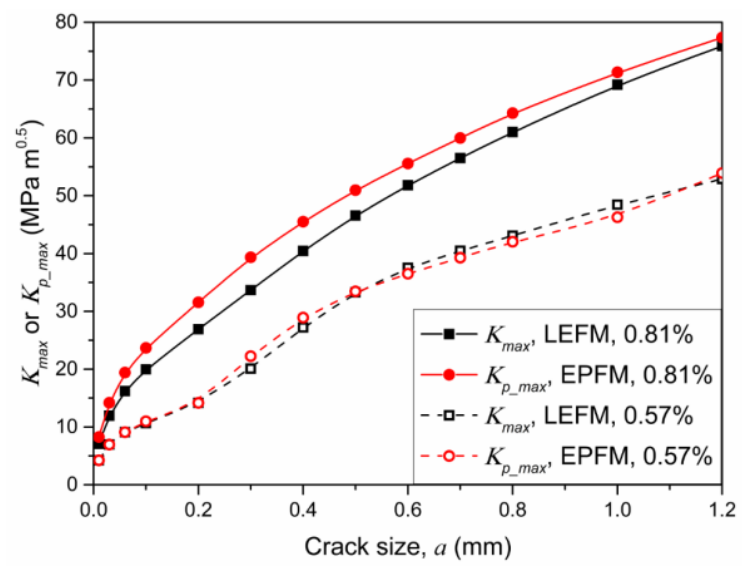

Fig. 18: Comparison between the LEFM and EPFM approaches in the TO shot peening condition at $\Delta \varepsilon_{x x}=0.81 \%$ and $0.57 \%$ for varying crack sizes.

Although the developed 2D FE model has been demonstrated to be effective and efficient in assessing the effects of strain hardening and residual stress (with associated redistribution during cyclic loading), it still has some limitations which require cautious consideration in future work. One is that due to the applied 2D plane strain assumption (corresponding to a through-thickness crack), the crack shape evolution, which was found significantly affected by shot peening [2], was not considered in this study. This might lead to less accurate evaluation of $K$ [38], thus affecting the life prediction results. Another limitation is that the microstructure of the material, which might significantly influence microstructurally short crack growth, was not taken into account in the developed model. This was limited by the employed material model, which only represented the macroscopic mechanical properties of the material. Solutions to these limitations may involve development of more robust (but also more complex) models, such as FE models containing 3D cracks describing the real crack shape, and crystal plasticity materials model including microstructural features, which are beyond the scope of this paper.

It is also noteworthy that the development of the current modelling methodology focusing on short crack growth is based on the general understanding of the fatigue behaviour in metals, and involves no unique assumptions that are only applicable to the current material system. Therefore, we believe that the application of this model can be extended to other metals, as long as the material model is appropriately calibrated and the shot peening induced effects (compressive residual stress and strain 
hardening) are accurately characterised (by either experimental, numerical or analytical approaches) to define the input of the model. In conditions where the crack initiation life plays a more important role (such as in HCF), the current model can be potentially used along with crack initiation criteria to enhance the accuracy of the life prediction.

\section{Conclusions}

This study has investigated a methodology to explicitly consider the shot peening effects in a lifing procedure, using both LEFM and EPFM approaches. The following major conclusions of the current study have been demonstrated.

- A 2D eigenstrain-based finite element model has been developed to accurately predict the residual stress relaxation behaviour in safety-critical shot-peened regions, considering the effects of compressive residual stresses and strain hardening caused by shot peening.

- The effects of shot peening on crack driving force have been investigated using LEFM and EPFM approaches; the weight function method was applied to calculate the stress intensity factor $(K)$ for the LEFM approach; the J-integral obtained using the 2D crack modelling was used to determine the equivalent stress intensity factor $\left(K_{p}\right)$ for the EPFM approach. It was found that shot peening improved fatigue life mainly by retarding the short crack growth process within the shot-peening-affected layer. The compressive residual stress caused by shot peening made the main contribution to this benefit by reducing the effective crack driving force, as a result of crack closure. However, strain hardening caused by shot peening (when considered explicitly and separately) was found to increase the crack driving force in this study, so is expected to lead to an accelerated crack propagation process. Conversely, the plastic deformation in the shot-peening-affected layer (before cracks appeared) was reduced by the strain hardening effects, implying a hindered crack initiation process.

- Fatigue life prediction has been carried out for the shot-peened notched specimens. The short crack growth behaviour in the shot-peened samples has been successfully correlated to the baseline long crack growth data (i.e. the Paris law) by taking crack closure induced by the compressive residual stress into account. Acceptable life prediction has been achieved using the EPFM approach, especially in the LCF regime where crack propagation played a more important role than crack initiation.

- The LEFM approach tends to result in non-conservative life predictions if it is applied in the LCF regime, which requires cautious consideration in application. In the HCF regime, a good consistency between the LEFM and EPFM approaches was demonstrated. 


\section{Acknowledgements}

Financial support from China Scholarship Council and the Engineering and Physical Sciences Research Council (EP/K503150/1) is gratefully acknowledged. The authors also acknowledge the support of the University of Southampton for access to its IRIDIS4 High Performance Computing Facility. Thanks are also extended to Dr Niall Smyth from the Coventry University for his assistance in gathering residual stress data and to Dr Katherine Soady from Uniper Technologies Ltd. for helpful discussions.

\section{Data access statement}

All data supporting this study are openly available from the University of Southampton repository at http://doi.org/10.5258/SOTON/403453.

\section{Reference}

[1] L. Wagner, Mechanical surface treatments on titanium, aluminum and magnesium alloys, Mat Sci Eng A, 263 (1999) 210-216.

[2] B.Y. He, K.A. Soady, B.G. Mellor, G. Harrison, P.A.S. Reed, Fatigue crack growth behaviour in the LCF regime in a shot peened steam turbine blade material, Int J Fatigue, 82 (2016) 280-291.

[3] I. Altenberger, B. Scholtes, U. Martin, H. Oettel, Cyclic deformation and near surface microstructures of shot peened or deep rolled austenitic stainless steel AISI 304, Mat Sci Eng A, 264 (1999) 1-16.

[4] K.A. Soady, Life assessment methodologies incoroporating shot peening process effects: mechanistic consideration of residual stresses and strain hardening Part 1 - effect of shot peening on fatigue resistance, Mater Sci Tech-lond, 29 (2013) 637-651.

[5] L. Wagner, G. Luetjering, Influence of shot peening on the fatigue behavior of titanium alloys, in: The First International Conference on Shot Peening, Paris, France, 1996, pp. 453-460.

[6] A.M. Eleiche, M.M. Megahed, N.M. Abd-Allah, The shot-peening effect on the HCF behavior of high-strength martensitic steels, J Mater Process Tech, 113 (2001) 502-508.

[7] C. You, M. Achintha, K.A. Soady, P.A.S. Reed, Low cycle fatigue life prediction in shot-peened components of different geometries - Part II: Life prediction, Fatigue Fract Eng M, 40 (2017) 749-760. [8] J. Liu, M. Pang, Fatigue life prediction of shot-peened steel, Int J Fatigue, 43 (2012) 134-141.

[9] M. Benedetti, V. Fontanari, C. Santus, M. Bandini, Notch fatigue behaviour of shot peened highstrength aluminium alloys: Experiments and predictions using a critical distance method, Int J Fatigue, 32 (2010) 1600-1611. 
[10] M. Benedetti, V. Fontanari, M. Bandini, A simplified and fast method to predict plain and notch fatigue of shot peened high-strength aluminium alloys under reverse bending, Surf Coat Tech, 243 (2014) 2-9.

[11] E.R.d.I. Rios, A. Walley, M.T. Milan, G. Hammersley, Fatigue crack initiation and propagation on shot-peened surfaces in A316 stainless steel, Int J Fatigue, 17 (1995) 493-499.

[12] M. Guagliano, L. Vergani, An approach for prediction of fatigue strength of shot peened components, Eng Fract Mech, 71 (2004) 501-512.

[13] E.R.D.L. Rios, M. Trull, A. Levers, Modelling fatigue crack growth in shot-peened components of Al 2024-T351, Fatigue \& Fracture of Engineering Materials and Structures, 23 (2000) 709-716.

[14] Y. Xiang, Y. liu, Mechanism modelling of shot peening effect on fatigue life prediction, Fatigue Fract Eng M, 33 (2010) 116-125.

[15] Y.K. Gao, X.R. Wu, Experimental investigation and fatigue life prediction for 7475-T7351 aluminum alloy with and without shot peening-induced residual stresses, Acta Mater, 59 (2011) 3737-3747.

[16] J.C. Newman, FASTRAN-2: a fatigue crack growth structural analysis program, NASA technical memorandum 104159, (1992).

[17] R.A. Cláudio, A. Burgess, C.M. Branco, J. Byrne, Failure analysis of scratch damaged shot peened simulated components at high temperature, Eng Fail Anal, 16 (2009) 1208-1220.

[18] R.A. Cláudio, J.M. Silva, C.M. Branco, J. Byrne, A fracture mechanics based approach to predict fatigue life of scratch damaged shot peened components, Procedia Engineering, 10 (2011) 2672-2677. [19] A. Blarasin, M. Guagliano, L. Vergani, Fatigue crack growth prediction in specimens similar to spur gear teeth, Fatigue Fract Eng M, 20 (1997) 1171-1182.

[20] K.A. Soady, B.G. Mellor, P.A.S. Reed, Life assessment methodologies incoroporating shot peening process effects: mechanistic consideration of residual stresses and strain hardening Part 2 approaches to fatigue lifing after shot peening, Mater Sci Tech-lond, 29 (2013) 652-664.

[21] C.A. Rodopoulos, S.A. Curtis, E.R. de Los Rios, J. SolisRomero, Optimisation of the fatigue resistance of 2024-T351 aluminium alloys by controlled shot peening-methodology, results and analysis, Int J Fatigue, 26 (2004) 849-856.

[22] M.H. El Haddad, K.N. Smith, T.H. Topper, Fatigue Crack Propagation of Short Cracks, Journal of Engineering Materials and Technology, 101 (1979) 42.

[23] M. Beghini, L. Bertini, Fatigue crack propagation through residual stress fields with closure phenomena, Eng Fract Mech, 36 (1990) 379-387.

[24] M.J. Pavier, C.G.C. Poussard, D.J. Smith, Effect of residual stress around cold worked holes on fracture under superimposed mechanical load, Eng Fract Mech, 63 (1999) 751-773. 
[25] X.R. WU, A.J. Carlsson, Weight functions and stress intensity factor solutions, Pergamon Press, Oxford, 1991.

[26] M.H. El Haddad, N.E. Dowling, T.H. Topper, K.N. Smith, J integral applications for short fatigue cracks at notches, Int J Fracture, 16 (1980) 15-30.

[27] M.S. Bruzzi, P.E. McHugh, Methodology for modelling the small crack fatigue behaviour of aluminium alloys, Int J Fatigue, 24 (2002) 1071-1078.

[28] C. You, M. Achintha, K.A. Soady, N. Smyth, M.E. Fitzpatrick, P.A.S. Reed, Low cycle fatigue life prediction in shot-peened components of different geometries - Part I: Residual stress relaxation, Fatigue Fract Eng M, 40 (2017) 761-775.

[29] K.A. Soady, B.G. Mellor, G.D. West, G. Harrison, A. Morris, P.A.S. Reed, Evaluating surface deformation and near surface strain hardening resulting from shot peening a tempered martensitic steel and application to low cycle fatigue, Int J Fatigue, 54 (2013) 106-117.

[30] K.A. Soady, B.G. Mellor, J. Shackleton, A. Morris, P.A.S. Reed, The effect of shot peening on notched low cycle fatigue, Mat Sci Eng A, 528 (2011) 8579-8588.

[31] M. Achintha, D. Nowell, K. Shapiro, P.J. Withers, Eigenstrain modelling of residual stress generated by arrays of laser shock peening shots and determination of the complete stress field using limited strain measurements, Surf Coat Tech, 216 (2013) 68-77.

[32] K. Dalaei, B. Karlsson, L.E. Svensson, Stability of shot peening induced residual stresses and their influence on fatigue lifetime, Mat Sci Eng A, 528 (2011) 1008-1015.

[33] X. Song, W.C. Liu, J.P. Belnoue, J. Dong, G.H. Wu, W.J. Ding, S.A.J. Kimber, T. Buslaps, A.J.G. Lunt, A.M. Korsunsky, An eigenstrain-based finite element model and the evolution of shot peening residual stresses during fatigue of GW103 magnesium alloy, Int J Fatigue, 42 (2012) 284-295.

[34] Y. Lei, N.P. O'Dowd, G.A. Webster, Fracture mechanics analysis of a crack in a residual stress field, Int J Fracture, 106 (2000) 195-216.

[35] Y. Lei, J calculation for a crack in a welding residual stress field following a FE welding simulation, Trans SMiRT, 23 (2015).

[36] K.A. Soady, Reducing conservatism in life assessment approaches: Industrial steam turbine blade to disc interfaces and the shot peening process, in: University of Southampton, 2013.

[37] P. Zhang, J. Lindemann, C. Leyens, Influence of shot peening on notched fatigue strength of the high-strength wrought magnesium alloy AZ80, J Alloy Compd, 497 (2010) 380-385.

[38] P.M. Scott, T.W. Thorpe, A critical review of crack tip stress intensity factors for semi-elliptic cracks, Fracture of Engineering Materials \& Structures, 4 (1981) 291-309. 